\title{
Review
}

\section{Ocular Outflow Facility with Emphasis on Neuronal Regulation of Intraocular Smooth Muscles}

\author{
Ryo Suzuki, MD \\ Department of Ophthalmology, Yamaguchi University School of Medicine, Ube \\ City, 755, Japan
}

The narrow range of intraocular pressure (IOP) $(12-20 \mathrm{mmHg})$ in normal individuals has stimulated a search for possible regulatory mechanisms ${ }^{7,18,65)}$ of aqueous production and outflow $^{6,46)}$. Compared with aqueous production, the aqueous outflow mechanisms of the neuronal, humoral, and mechanical processes have been studied much less. Because the eye constitutes a small portion of total body mass, it is very difficult to determine the neuronal and mechanical regulations of intraocular muscle and outflow facility. Locally acting mechanisms, should be an ideal means for integrating its physiology ${ }^{58,76)}$. The peripheral nervous system is designed to effect such local control. Because most available antiglaucoma agents interact with the autonomic mechanisms and mechanical activities of the smooth muscles in the eye $^{53,59,68)}$, combined studies of the intraocular muscles with eye perfusion ${ }^{7,66)}$ and cell shape changes of cultured cells from the outflow route ${ }^{22,66)}$ would suggest the role of the nervous system in regulating IOP.

From an historical view point, much speculation and minimal experimentation have been focused on the influence of the iris sphincter, the iris dilator, and the ciliary muscles on aqueous humor outflow. Accommodation, cholinergic agonists, and stimulation of the oculomotor nerve, all increase outflow facility ${ }^{19}$, whereas ganglionic blocking agents and anticholinergic drugs decrease the ocular outflow facility ${ }^{5,66)}$. Furthermore, the outflow facility increase with intravenous pilocarpine administration is instantaneous, suggesting that the effect is mediated by an arterially perfused tissue ${ }^{31,32,46)}$. Following disinsertion of the ciliary muscle, the outflow facility did not increase with the application of pilocarpine ${ }^{32)}$. All things considered, these findings suggest that intraocular muscle tone somehow alters the meshwork so as to increase outflow facility during ciliary muscle contraction and decrease facility during ciliary muscle relaxation ${ }^{66)}$.

Because the primary function of the trabecular meshwork is to maintain the appropriate aqueous humor outflow rate and IOP, the focus of outflow pathway research should be on the

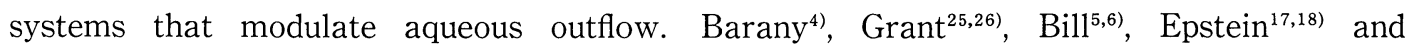
Kaufman $^{31,32)}$ greatly contributed to this body of knowledge.

The outflow resistance in the conventional outflow route can be altered by changes in intraocular muscle tone ${ }^{35,59,72)}$ and direct effects on the trabecular meshwork ${ }^{48,66,70)}$. In the present review, neuronal and mechanical influences on the intraocular muscle and outflow facility of the aqueous humor are discussed. 


\section{Open-angle glaucoma or angle-closure glaucoma?}

The iris sphincter and ciliary muscles are primarily cholinergically innervated and contract in response to muscarinic agonists. In primates, the iris inserts into the ciliary muscle posterior to the scleral spur, and the ciliary muscle inserts at the scleral spur and at the posterior inner aspect of the trabecular meshwork ${ }^{39,69)}$.

When iridectomy or an opening in the peripheral iris is performed on an eye with angleclosure glaucoma, the new opening in the iris allows the iris to fall away from the angle, giving free access to the trabecular area and avoiding pupillary block formation (Fig. 1). Thus, because iridectomy theoretically relieves most relative pupillary block and closure of the anterior chamber angle, in the present review, only open-angle glaucoma is discussed as glaucoma.

\section{Why does IOP increase?}

As has been well described ${ }^{18)}$, Table 1 illustrates the relationship between IOP, the coefficient rate of outflow facility $(\mathrm{C})^{20,29)}$, and episcleral venous pressure $(\mathrm{Pe})$. The experimental method to determine the outflow facility of the eye is illustrated in Figs. 2 and 3. An advanced method to determine the outflow facility was developed (Fig. 2) ${ }^{65}$. However, outflow facility

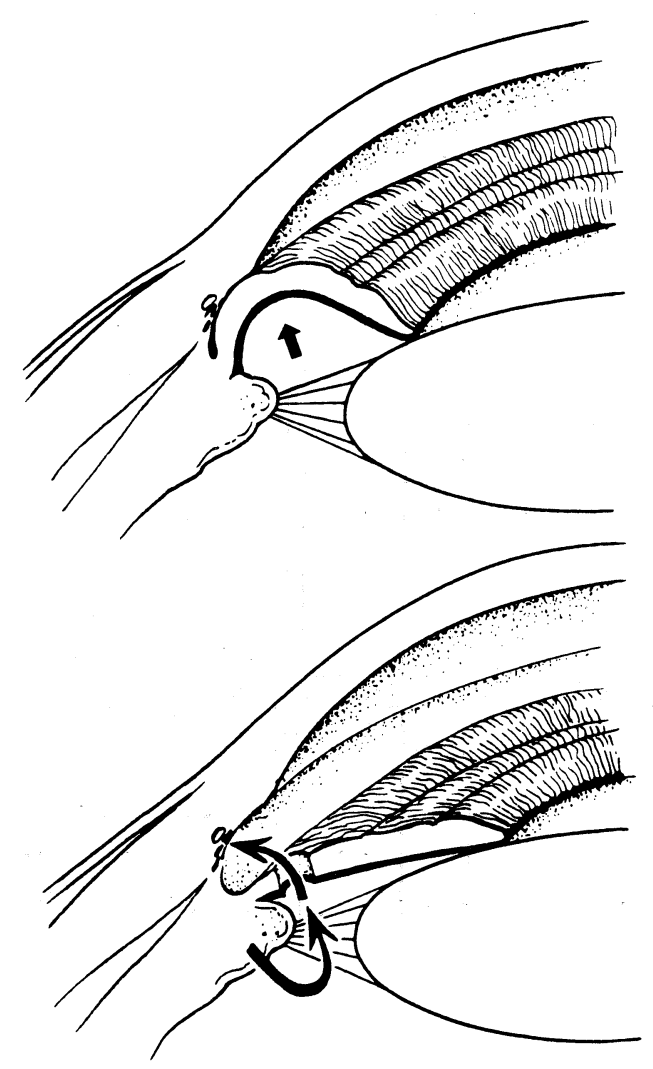

Fig. 1. Primary angle-closure glaucoma (PACG) and primary open-angle glaucoma (POAG). Buldged iris or pupillary block glaucoma is relieved by iridectomy, thus PACG theoretically changes to openangle glaucoma. Top, PACG; bottom, POAG. 


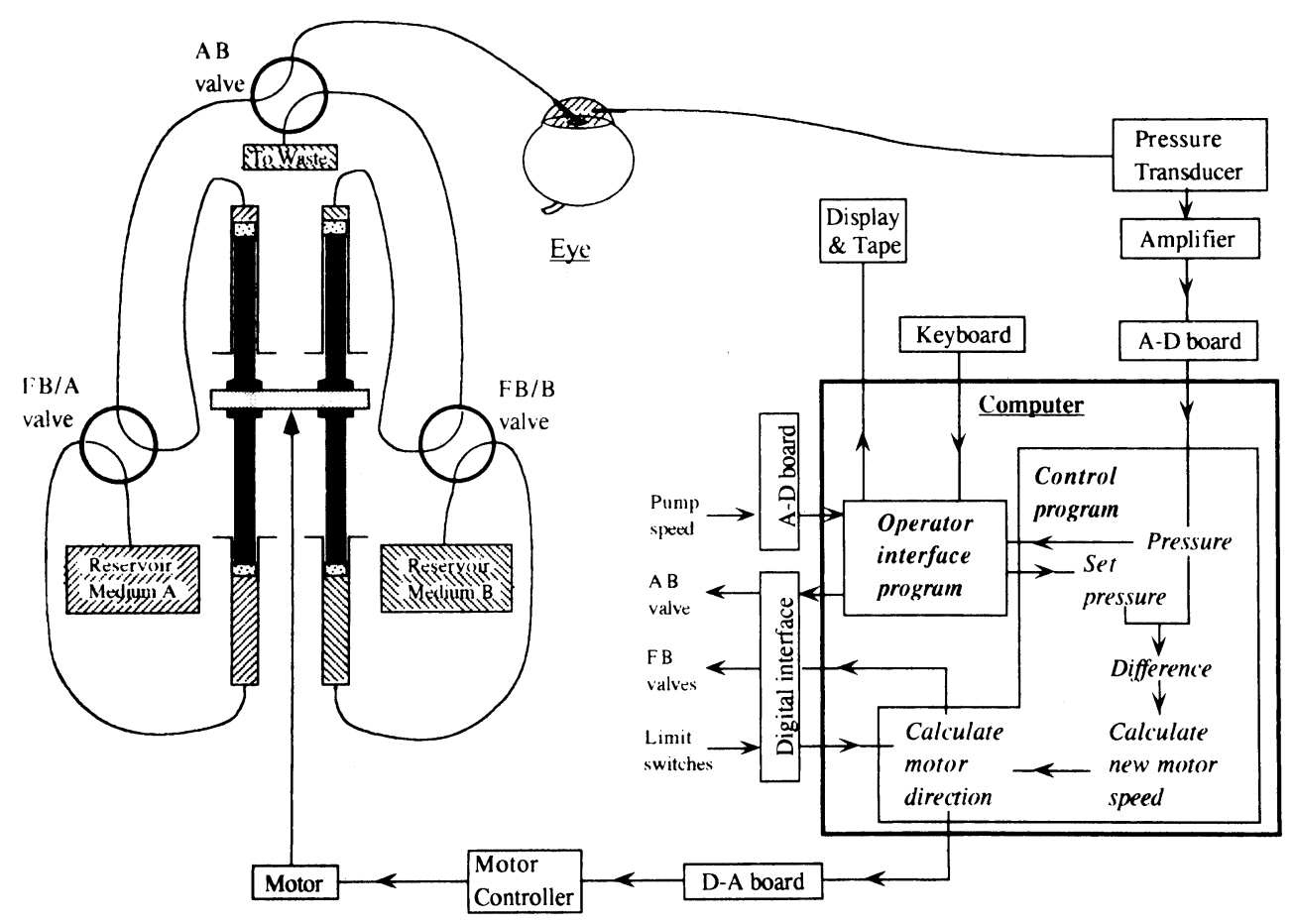

Fig. 2. Ocular perfusion method. An advanced type ${ }^{65)}$. The eye can be perfused with various pressures (Suzuki et al.; 1992, 1996).

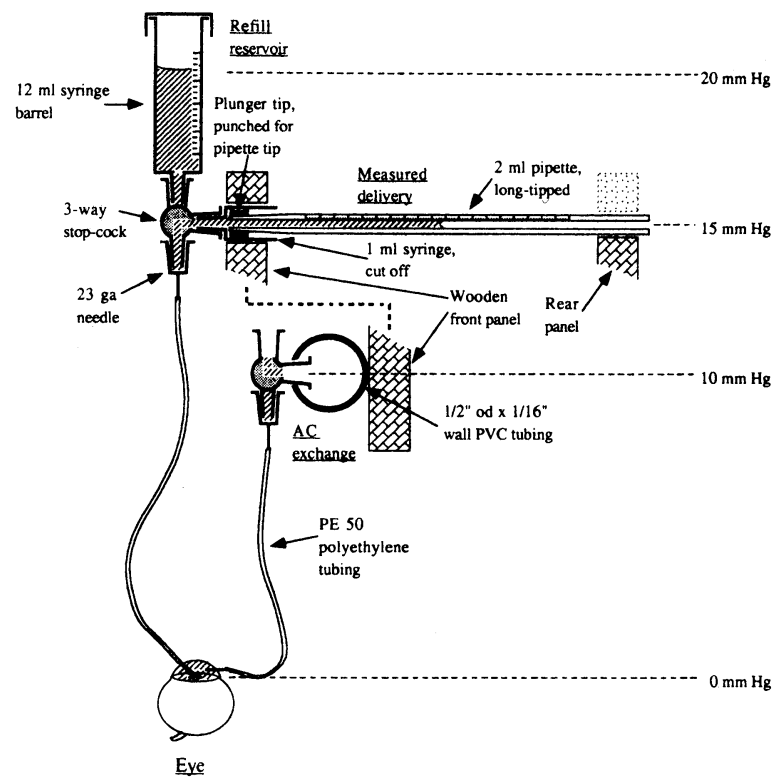

Fig. 3. Ocular perfusion method. A much simpler type ${ }^{65)}$. The eye is perfused with a constant pressure (Suzuki et al.; 1992, 1996). 
can be measured ${ }^{6566)}$ using a much simpler method (Fig. 3) ${ }^{66)}$. With normal parameter (Table 1), a two-fold change in the rate of aqueous formation causes only a $4 \mathrm{mmHg}$ change in IOP (13 to $17 \mathrm{mmHg}$ ). In contrast, in a glaucomatous eye, a two-fold change in the rate of aqueous formation causes a $20 \mathrm{mmHg}$ change in IOP instead of the $4 \mathrm{mmHg}$ change seen in the normal eye. Furthermore, in the glaucoma, an increase in the outflow facility of $0.05 \mu 1 / \mathrm{min} / \mathrm{mmHg}$ reduces the IOP by $15 \mathrm{mmHg}$ (39 to $24 \mathrm{mmHg}$ ) in contrast with a $1 \mathrm{mmHg}$ reduction in the normal eye. Thus, glaucomatous eyes have greater pressure variations than normal eyes in response to changes, especially in the outflow facility. Drugs that influence the outflow facility cause greater changes in pressure in glaucomatous than in normal eyes.

The relationship between the extent of closure of the filtration angle by synechia or by apposition of the iris to the trabecular meshwork also is seen in Table 1. Obstruction of half the circumference reduces the outflow facility by $50 \%$, and obstruction of three quarters of the circumference reduces the outflow facility by $75 \%$. Closing the filtration angle by half of the circumference raises the pressure in both eyes, to only $19 \mathrm{mmHg}$ in the normal eye, but to 29 $\mathrm{mmHg}$ in the poor normal eye. Similarly, with closure of three quarters of the angle, the difference between the eyes is still more drastic, ie, $29 \mathrm{mmHg}$ compared with $49 \mathrm{mmHg}$.

Table 1. Examples of difference in the degree to which the IOP is calculated to be affected by changes in flow (F) and facility of outflow (C) in different types of eyes. Originally presented by Chandler and Grant (Epstein) (1994) and modified by Suzuki (1996).

\begin{tabular}{|c|c|c|c|c|}
\hline & $\mu 1 / \min (\mathrm{F})$ & $\mu \mathrm{l} / \mathrm{min} / \mathrm{mmHg}(\mathrm{C})$ & $\mathrm{mmHg}(\mathrm{Pe})$ & $\mathrm{mmHg}(\mathrm{IOP})$ \\
\hline & & $(\mathrm{F} \div \mathrm{C})+$ & $=\mathrm{IOP}$ & \\
\hline \multirow[t]{3}{*}{ Normaal } & 1.5 & 0.25 & 9 & 15 \\
\hline & 1 to 2 & 0.25 & 9 & 13 to 17 \\
\hline & 1.5 & 0.3 & 9 & 14 \\
\hline \multirow[t]{3}{*}{ Glaucoma } & 1.5 & 0.05 & 9 & 39 \\
\hline & 1 to 2 & 0.05 & 9 & 29 to 49 \\
\hline & 1.5 & 0.10 & 9 & 24 \\
\hline Good normal & 1.5 & 0.3 & 9 & 14 \\
\hline $1 / 2$ angle closd & 1.5 & 0.15 & 9 & 19 \\
\hline $3 / 4$ angle closd & 1.5 & 0.075 & 9 & 29 \\
\hline Poor normal & 1.5 & 0.15 & 9 & 19 \\
\hline $1 / 2$ angle closd & 1.5 & 0.075 & 9 & 29 \\
\hline $3 / 4$ angle closd & 1.5 & 0.0375 & 9 & 49 \\
\hline Standerd & 1.5 & 0.3 & 9 & 14 \\
\hline \multirow[t]{3}{*}{ Inflow } & 0.75 & 0.3 & 9 & 11.5 \\
\hline & 0.375 & 0.3 & 9 & 10.3 \\
\hline & 3 & 0.3 & 9 & 19 \\
\hline \multirow[t]{4}{*}{ Outflow } & 1.5 & 0.15 & 9 & 19 \\
\hline & 1.5 & 0.075 & 9 & 29 \\
\hline & 1.5 & 0038 & 9 & 49 \\
\hline & 1.5 & 0.019 & 9 & 89 \\
\hline
\end{tabular}


Even if the inflow is one-half or one-quarter, the pressure reduction is only $2.5 \mathrm{mmHg}$ (14 to $11.5 \mathrm{mmHg}$ ) or $3.7 \mathrm{mmHg}$ (14 to $10.3 \mathrm{mmHg}$ ) (Table 1). If the inflow is doubled, the IOP increase is only $5 \mathrm{mmHg}$. By contrast, when the outflow facility is decreased from 0.3 to 0.15 , $0.075,0.038$, and 0.019 , the IOP increase is much greater, ie, $5,15,35$, and $75 \mathrm{mmHg}$ (14 to 89 $\mathrm{mmHg}$ ). Therefore, the outflow facility is most important for understanding and curing glaucoma. This is the focus of this review. Nevertheless, experimental studies in this important field are scarce ${ }^{7,23,65)}$.

\section{Trabecular meshwork}

The aqueous outflow pathway has not been well studied physiologically, because it is small and difficult to access. According to Acott ${ }^{2}$, the human trabecular meshwork is small (100-150 $\mu \mathrm{g})$ with few cells $(200,000-300,000$ per eye) that are highly differentiated and moderately

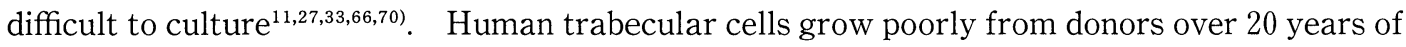
age. Human, monkey, and bovine trabecular meshwork extracts, cell cultures, and human corneoscleral organ cultures have been the primary focus of molecular analysis of the outflow pathway $^{1,48,66)}$.

According to Grant ${ }^{26)}$, removal of the trabecular meshwork in enucleated human eyes

Table 2. Intraocular distribution of neurotransmitters and autacoids in mammalian eyes

\begin{tabular}{|c|c|c|c|}
\hline $\begin{array}{c}\text { Neurotransmitters } \\
\text { Autacoids }\end{array}$ & Intraocular muscle & $\begin{array}{l}\text { On and around } \\
\text { Trabecular meshwork }\end{array}$ & $\begin{array}{l}\text { Drainage } \\
\text { route }\end{array}$ \\
\hline acetylcholine & H & + & + \\
\hline $\mathrm{BNP}^{*}$ & ? & + & $-?$ \\
\hline CGRP* & + & + & H \\
\hline cholecystokini & $+?$ & + & $?$ \\
\hline dopamine & $-?$ & $?$ & + \\
\hline dynorphin & $+?$ & ? & + \\
\hline endothelin & + & + & ? \\
\hline enkepharin (Leu-, Met-) & + & ? & ? \\
\hline galanin & $?$ & + & H \\
\hline neuropeptide Y & + & + & H \\
\hline neurotensin & + ? & - & + \\
\hline nitric oxide & + & + & + \\
\hline norepinephrine & H & $-?$ & + ? \\
\hline $\mathrm{PHI}^{*}$ & $-?$ & - & + \\
\hline prostaglandins & + & + & + \\
\hline serotonin & + & $?$ & + \\
\hline substance $\mathrm{P}$ & + & $+?$ & H \\
\hline VIP* & + & + & + \\
\hline
\end{tabular}

Modified from Stone $\mathrm{RA}^{63)}$. The galanin data apply only to the cat, since there is marked species variability. The data on BNP are from the pig eye. Dynorphine was identified in the guinea pig iris.

${ }^{*}$ CGRP, calcitonin gene-related peptide; BNP, brain natriuretic peptide ; PHI, peptide histidine isoleucine. 
decreases the outflow resistance by $75 \%$, which indicates that the primary resistance is in the trabecular meshwork, most probably within the cribriform layer. In the monkey eye, the primary pressure decrease occurs between the anterior chamber and Schlemm's canal, whereas there is only a minimal difference in pressure between the canal and the episcleral veins ${ }^{5,47)}$. Most of the resistance is between the anterior chamber and Schlemm's canal ${ }^{25}$.

\section{Peripheral nerves and IOP}

The trabecular meshwork is innervated by both the cholinergic and the adrenergic nervous systems, in addition to sensory innervation ${ }^{58)}$. Many different peptidergic (VIP ${ }^{57,58)}$, neuropeptide $\mathrm{Y}, \mathrm{CGRP}^{28)}$, substance $\mathrm{P}^{62,80}$ etc) nerve fibers are present, but the significance of the trabecular innervation in relation to aqueous humor outflow is still largely unknown (Table 2). For example, presumed serotonergic nerve fibers are present in the ciliary body, serotonin is in human aqueous humor, and serotonergic agents alter IOP ${ }^{58,71)}$. The serotonergic antagonist, ketanserin, lowers IOP in humans. Because serotonin is localized in the anterior segment nerves ${ }^{58)}$, neuronal or other mechanisms may underlie these pharmacologic effects. The effects on intraocular muscle tissue should be studied.

Leu-enkepharine is another example and probably derives from cholinergic neurons of the ciliary ganglion. Opioid mechanisms ${ }^{15,30)}$ appear to influence the IOP, by affecting outflow ${ }^{18,26)}$. As shown in Table 2, there are many peptides and purines distributed in intraocular muscles or the drainage, but most studies have been restricted only to morphology or immunohistochemical staining ${ }^{56,58)}$.

\section{Cholinergic regulation}

The roles of the iris and the ciliary muscle in mediating outflow facility ${ }^{20)}$ were clarified by two studies. First, removal of the iris alone did not affect IOP, resting outflow facility, and facility responses to pilocarpine. Therefore, it is clear that the ability of the outflow facility to increase the effects of pilocarpine is not mediated by the iris. Second, after disinsertion of the ciliary muscle from its proximal attachment, pilocarpine did not effect outflow facility. Therefore, several studies concluded that the facility-increasing effects of pilocarpine and probably other cholinergic drugs are the results of ciliary muscle contraction, with no measurable effect directly on the meshwork ${ }^{31,32,47,66)}$. As pilocarpine ${ }^{55)}$ increases the outflow facility, it stops the uveoscleral outflow almost completely, whereas atropine increases uveoscleral outflow ${ }^{46,47)}$.

Surgery performed on monkeys is much more difficult than on human eyes. The auther is surprised to see the monkey results ${ }^{31}$.

\section{Ciliary muscle and aqueous humor outflow}

The attachment of the trabecular meshwork to the anterior parts of the ciliary muscle bundles makes it possible for the ciliary muscle to alter the configuration of the trabecular 


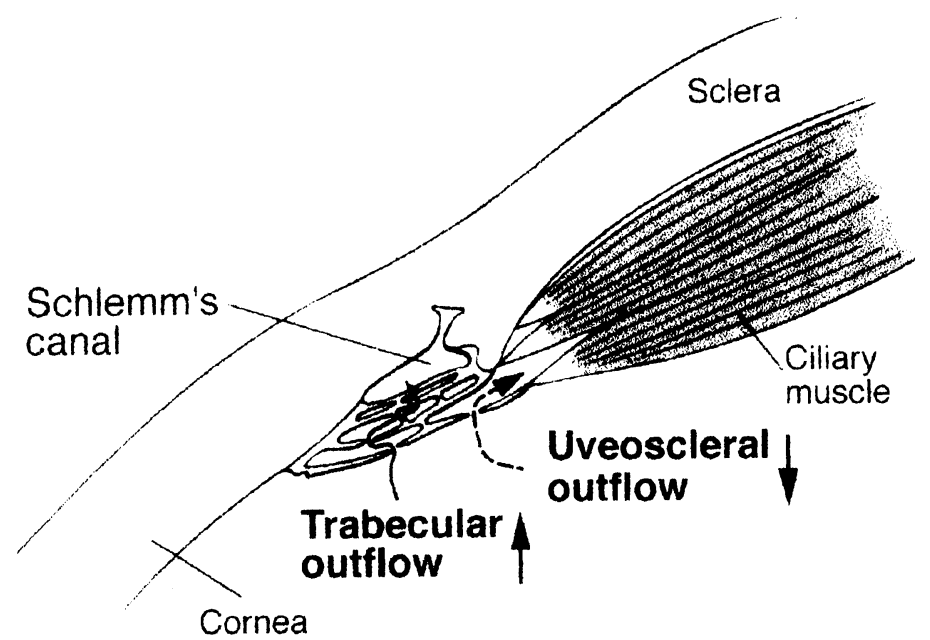

Fig. 4. Ciliary muscle contraction. The conraction decreases uveoscleral outflow and increases trabecular outflow (Modified from Nilsson ${ }^{47)}$ and originally proposed by Bill ${ }^{6)}$ ).

meshwork ${ }^{47)}$. When the ciliary muscle contracts (Fig.4), the anterior part of the muscle thickens, and the meshwork moves toward the anterior chamber, making the meshwork packing looser ${ }^{5}$. The widening of the spaces between the sheets in the meshwork increases the facility in the meshwork. Simultaneously, the spaces between the ciliary muscle bundles narrow and prevent uveoscleral outflow ${ }^{6}$. In other words, when the ciliary muscle contracts $^{36,37,59,78)}$, the spaces between the muscle bundles obstruct aqueous humor drainage via the uveoscleral route ${ }^{6,69}$. The effect of trabecular drainage is greater than the effect of the obstruction of uveoscleral drainage, so that the net effect is decreased IOP. On the other hand, when the ciliary muscle relaxes (Fig. 5), the muscle bundle becomes thinner and the spaces

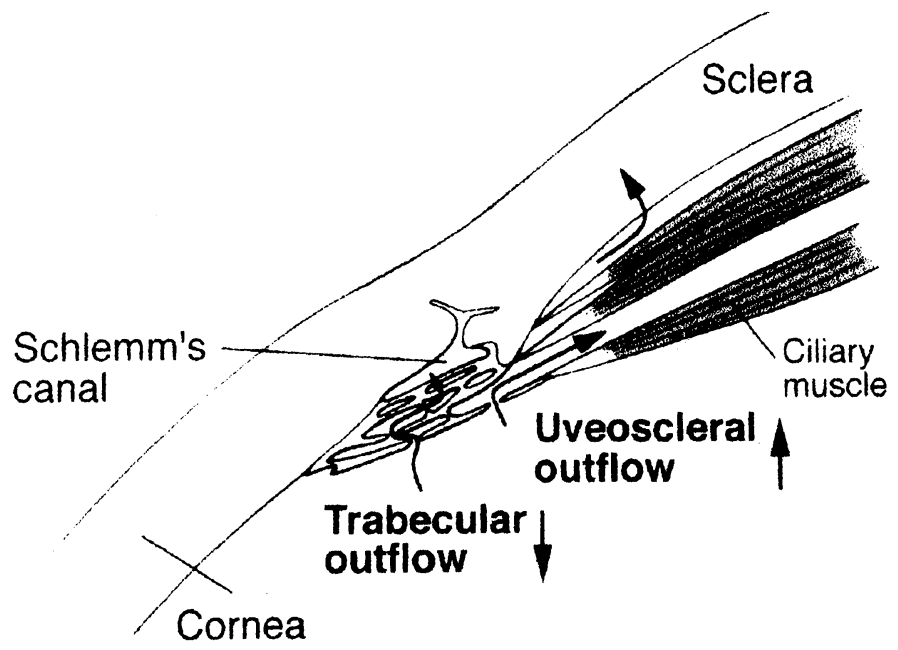

Fig. 5. Ciliary muscle relaxation. The relaxation increases uveoscleral outflow and decreases trabecular outflow (Modified from Nilsson ${ }^{47)}$ and originally proposed by Bill ${ }^{6)}$ ). 
widen; thus, uveoscleral outflow increases ${ }^{47}$. Therefore, depending on the degree of contraction in the ciliary muscle, the aqueous humor can be redistributed via the conventional or the uveoscleral outflow route (Figs. 4, 5).

The other major function of the ciliary muscle is accommodation. The accommodative myopia induced by cholinomimetic antiglaucoma drugs is a major disadvantage to their use, especially in younger patients. The ciliary muscles show a ripple formation ${ }^{59)}$. Recording of the ciliary muscle was first accomplished in bovine tissue. This ccontractile activity makes the ciliary muscle capable of graded, sustained contractions. Because of the anatomic association between the anterior muscle tendons and the trabecular meshwork, this contraction mechanically deforms the meshwork and widens the canal in such a way that the outflow facility increases $^{6,52)}$.

\section{Lack of obstruction in the uveoscleral route}

Muscarinic agonists do not appear to have any direct facility-increasing effect on the trabecular meshwork. In the author's experiment, carbachol or pilocarpine was administered to bovine eyes, and the outflow facility did not increase. This is very curious, because carbachol and/or pilocarpine contracts human ciliary muscle, thus opening the trabecular meshwork pores. To our great surprise, no in vitro experiment has successfully demonstrated that muscarinic agonists increase trabecular outflow.

VIP increases Ach release ${ }^{62)}$ from cholinergic nerve terminals of the bovine ciliary muscle without changing the muscle tone ${ }^{59)}$. VIP ${ }^{56,71)}$ relating to the cholinergic nerves, causes a slight increase in outflow facility in the monkey ${ }^{45,47)}$. Because VIP also is a potent stimulator of the adenylate cyclase system, VIP may increase the facility via cAMP.

Why can aqueous pass through the uveoscleral route? According to Nilsson and Bill ${ }^{47)}$, the lack of an epithelial barrier between the anterior chamber and the ciliary body makes it possible for aqueous humor to enter the ciliary body from the chamber angle. The aqueous can pass between the muscle bundles and thus enter the supraciliary and suprachoidal spaces ${ }^{6)}$. Outside the eye, the fluid becomes part of the orbital tissue and is partly reabsorbed into the orbital blood vessels.

The uveoscleral outflow is relatively pressure insensitive within the normal range of IOP, because the driving force of uveoscleral outflow is the difference in pressure between the anterior chamber and the suprachoroidal space ${ }^{47)}$. The pressure in the suprachoroidal space is slightly lower than the IOP in the monkey. An increase in the IOP causes an almost equal change in the suprachoroidal pressure, thus keeping the uveoscleral outflow pressure relatively constant ${ }^{16)}$. When the IOP increases, the ciliary muscle and supraciliary space compress, causing decreased outflow facility of the uveoscleral flow ${ }^{6,16}$.

\section{Dissociation between outflow facility and accommodation}

Longitudinal fibers of the ciliary muscle primarily work on outflow facility, whereas circular fibers subserve accommodation. However, a dissociation was observed between the 
effects of pilocarpine on accommodation and outflow facility ${ }^{19,20)}$. Further, even though a normal accommodative response to pilocarpine and physostigmine maintained in the re-innervated monkey eye after ciliary ganglionectomy, outflow facility did not increase in response to pilocarpine ${ }^{31,67)}$, whereas physostigmine increased the outflow facility. Further, intracameral injection of aceclidine, in contrast to pilocarpine, causes substantial increases in outflow facility with minimal accommodation ${ }^{20)}$. The aceclidine-induced facility response should be mediated by the ciliary muscle. Thus, the functions of outflow facility and accommodation can be dissociated pharmacologically or regulated by different types of receptors, as was well reviewed by Erickson-Lamy ${ }^{20)}$. However, as will be discussed, muscarinic receptor subtypes of the two muscle bundles seem the same in the same animal, and thus, therapeutic benefits are unlikely.

\section{Dissociation between uveoscleral outflow and ciliary muscle relaxation}

Topical PG F2 $\alpha$ and the isopropyl ester decrease IOP in rabbits, cats, monkeys ${ }^{24,46,50)}$, and humans ${ }^{3,73)}$, which was reviewed by Kaufman and Mittag ${ }^{32)}$. The hypotensive action of PG F2 $\alpha$ has been attributed to an increase in uveoscleral outflow, with little effect on trabecular facility.

Morphologic study of the monkey ciliary muscle after application of PG F2 $\alpha$ over several days shows narrowing of the muscle bundles, with widening of the spaces and a reduction in types 1 and 3 collagen between the muscle bundles. This structural alteration may explain the observed increase in uveoscleral outflow. However, it seems unlikely that such anatomic changes could occur rapidly enough to account for the increase in uveoscleral outflow after a single topical application of PG F2 $\alpha$.

Thus, a change in ciliary muscle tone ${ }^{59,72)}$ is one possible explanation for the acute effect of PG F2 $\alpha$. Results of studies on the effect of PG F2 $\alpha$ on ciliary muscle tone are contradictory; PG F2 $\alpha$ relaxed the Ach-contracted ciliary muscles of cats, rabbits, monkeys, and humans $^{72)}$. Some ${ }^{10,59,81)}$ reported no effect of PG F2 $\alpha$ on ciliary muscle tone. However, PG F2 $\alpha$ affected the bovine ciliary muscle tone ${ }^{37}$. We found no effect of PG F2 $\alpha$ on bovine ciliary muscle tone ${ }^{59)}$. Although the effects on ciliary muscle vary, PG F2 $\alpha$ increases uveoscleral outflow and antagonizes resting myopia in the monkey.

In living monkey studies, tonic accommodation averages approximately two diopters and is reversed partially by PG F2 $\alpha$ isopropylester (PG F2 $\alpha$-IE $)^{12)}$. The related ciliary muscle relaxation reduces accommodation (circular portion) and enhances uveoscleral outflow (longitudinal portion).

The ocular hypotensive effects of PGs seem to be the result of their ability to increase uveoscleral outflow. This occurs partly as a result of ciliary muscle relaxation ${ }^{5,6)}$, but structural changes within the muscle also contribute as stated previously ${ }^{39}$. Epinephrine may partly exert its hypotensive effect via the release of PGs, because hypotension is reduced by PG synthesis inhibitors ${ }^{8,9}$.

However, the effect of PGF2 $\alpha$ may not be caused by ciliary muscle relaxation. When the effect of the topical application of PGF $2 \alpha$ on refraction and accommodation was examined, topical PGF2 $\alpha$ reduced the IOP, but the patients' accommodation power did not change 
significantly. The amplitude of accommodation was unchanged, which may suggest that IOP reduction is caused by a mechanism other than ciliary muscle relaxation ${ }^{59}$.

It remains to be clarified whether or not endogenous PGs have a physiologic function in regulating uveoscleral outflow. We cannot deny that the PG effect may be pathophysiologic, and an increase in uveoscleral outflow may be associated with ocular inflammation, because in rabbits, the pressure reduction was inhibited by the application of indomethacin. Species differences are remarkable, because the outflow facility was increased in the bovine eye when treated with indomethacin.

\section{Muscarinic receptor subtype and cooperative iris responses}

There may be some regionalization of the accommodative and outflow functions within the ciliary muscle. Muscle fibers bundles are grouped in three major orientations, and the directional force exerted by each group differs. We should characterize such regionalization and determine whether the accommodative and outflow functions may be mediated by different subtypes of muscarinic receptor as suggested by Kaufman and Mittag ${ }^{32}$. We may some day use subtype-specific agonists to maximize outflow-mediating contraction while minimizing accommodation-mediating contraction.

The same strategy can be used to minimize pupillary constriction caused by cholinergic drugs. Induction of miosis ${ }^{19,32}$ is useful in the treatment of glaucoma to pull the iris root away from the trabecular meshwork. However, inducing miosis is presently disadvantageous in elderly patients with incipient cataracts, because miosis can significantly impair visual acuity.

Some muscarinic antagonists are partly selective for mydriasis as compared with cycloplegia, which suggests a difference in receptors on the two muscles. The dominant pupillary

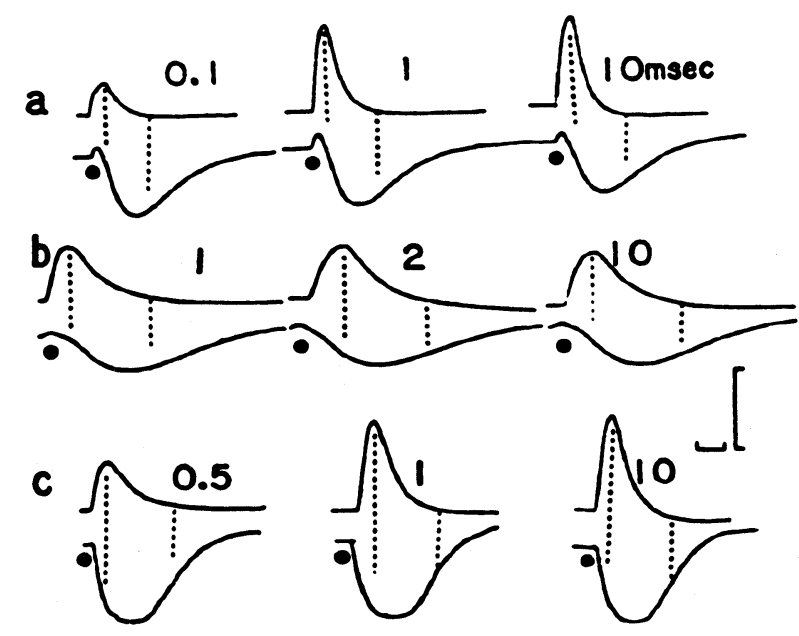

Fig. 6. Typical responses of the three representative muscles of the bovine iris sphincter (top tracing) and the dilator (bottom tracing). The iris sphincter reacted faster than the dilator. Electrical stimulation was applied at dots: a : $0.1,1$ and 10 msec pulse widths, 3 $\mathrm{Hz}, 1.5$ pulses ; b : 1,2 , and $10 \mathrm{msec}$ pulse widths, $5 \mathrm{~Hz}, 2.5$ pulses ; $\mathrm{c}: 0.5,1$, and $10 \mathrm{msec}$ pulse widths, $20 \mathrm{~Hz}, 10$ pulses. 
constriction is via the muscarinic receptor of the iris sphincter, and the cholinergic stimulation, in turn, causes iris dilator relaxation ${ }^{60,77)}$. When cholinergic miosis occurs, sphincter muscle contraction and dilator relaxation work together ${ }^{31,53,55,60,63,68,77)}$ (Fig. 6) with a different receptor subtype $^{34,41)}$. This possibility seems beneficial for older patients who have a small pupil.

However, this is unlikely, because cholinergic contraction of the iris sphincter and cholinergic relaxation in bovine dilator muscle occur via the same subtype of the muscarinic Ach

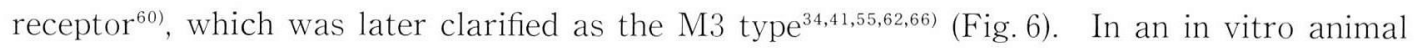
experiment, the mechanism of cholinergic contraction and relaxation of the iris is very complex, according to Takayanagi ${ }^{30,34,55,67)}$ and Watanabe ${ }^{41,44,53)}$. Furthermore, it is open to question how the iris physiology is involved in regulation of IOP and outflow facility.

\section{Muscarinic receptors around outflow channels of the iris}

Furthermore, the M3 receptor predominates in isolated cat irides, radioligand studies using subtype-specific antagonists ${ }^{10)}$, and Northern blot analysis using subtype-specific oligonucleotide probes ${ }^{29)}$. According to Zhang ${ }^{82)}$, the human ciliary muscle expresses the mRNA of all five subtypes of muscarinic receptors. This was determined by in situ hybridization and/or Northern blot analysis in intact tissue samples and cultured ciliary muscle cells. Interestingly, as reviewed by Erickson-Lamy ${ }^{20}$, in some individuals there may be a preponderance of $\mathrm{m} 5$ in the longitudinal portion of the muscle, and $\mathrm{m} 3$ in the circular portion of the muscle.

Muscarinic receptors are expressed in the trabecular meshwork and $\mathrm{m} 3$ receptors are present in cultured trabecular meshwork cells. Some expression in the ciliary muscle may be related to vascular tissue in the ciliary body, rather than to ciliary muscle cells per se. Studies of the monkey eye suggest that both outflow facility and accommodation responsiveness to pilocarpine are mediated by the M3 receptor ${ }^{19,21)}$.

The presence of muscarinic receptors, primarily of subtype M3, has been identified in
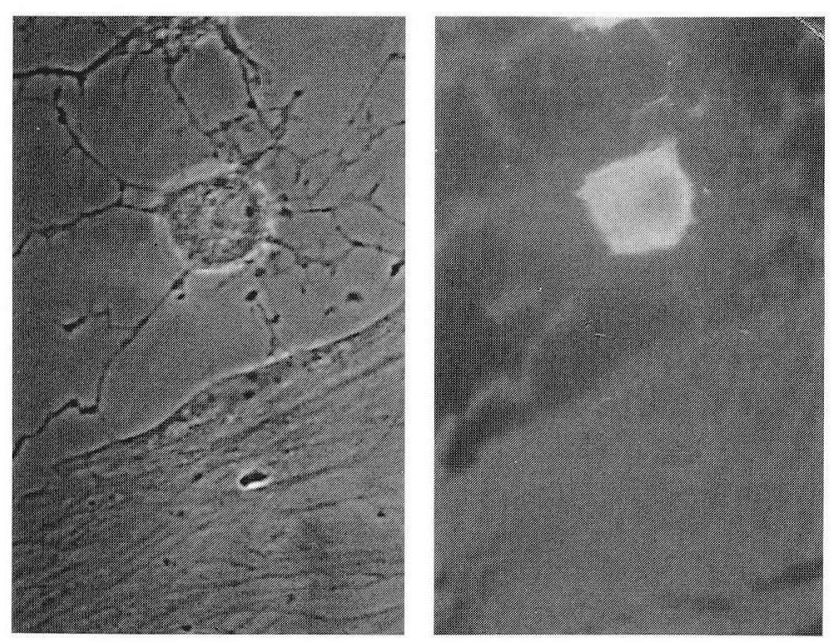

Fig. 7. Tissue culture of trabecular meshwork and smooth muscle. Left, phase contrast ; right, actin staining. 
human and bovine trabecular endothelial cells ${ }^{66)}$. In addition, cells containing smooth muscle actin and myosin have been identified in the meshwork (Fig. 7). Bovine meshwork itself has contractile properties, perhaps independent of the ciliary muscle ${ }^{33,66)}$. Thus, it is possible to devise a therapeutically useful cholinergic that acts on the meshwork itself.

The author is studying cholinergic effects on aqueous humor outflow caused by the mechanical effects of ciliary muscle contraction ${ }^{59)}$. Muscarinic receptors are present in ciliary muscle and other anterior segment structures, but we could not find evidence for a significant increase of outflow facility in vitro. The physiologic roles of receptor subtypes and their distribution in the ciliary muscle and the trabecular meshwork should be clarified.

\section{Indirectly acting cholinergic agents}

Interestingly, we found that Ach (up to $10^{-5} \mathrm{M}$ ) alone did not contract the iris sphincter muscle ${ }^{64)}$. Ach contracts other smooth muscles from low concentrations. The degree of Ach potentiating effect by anti-cholineesterases (anti-chEses) on cardiac, skeletal, and smooth muscles varied from 1.10- to 300-fold, compared with Ach alone. The lowest threshold concentration ever reported was decreased 1,000 -fold by eserine, in the case of electroplax ${ }^{52}$. The present experiments showed that Ach required a 12,000 times higher concentration than carbachol (Cch) to evoke the same iris muscle contraction. Thus, the difference in potency of Ach and Cch is unexpectedly great in intraocular muscle tissue ${ }^{63,64)}$.

Physostigmine (eserine) and neostigmine block AchE, and prevent metabolic inactivation of Ach release frm cholinergic nerve terminals. When AchE is blocked, the concentration of endogenously released Ach and its time of action is increased, as reviewed by Nardin and Zimmerman ${ }^{43)}$. Because the transmitter accumulates in large quantities at the neuromuscular junction, the endogenous cholinergic response is increased and prolonged ${ }^{64)}$. AntichEses have very strong cholinergic activity and a much longer duration of action in their IOP lowering ability than pilocarpine ${ }^{42)}$.

The use of AchE inhibitors to treat glaucoma is decreasing greatly because of their substantial adverse ocular effects ${ }^{43)}$. Extreme miosis occurs within half an hour of administration of eserine, and maximal IOP reduction occurs within 24 hours. Pressure reduction is extremely long-lasting, ie, from several days to two weeks. These agents unfortunately cause iris cysts and cataract ${ }^{43)}$. Because AchEse is present in the lens capsule, the agent increases lens hydration, resulting in lens opacity.

Anti-chE medications should be used to treat glaucoma in cases in which the patient has become intolerant of pilocarpine. The chE inhibitor is very effective in glaucoma of aphakia or pseudophakia ${ }^{51)}$. In uncontrolled glaucoma treated with pilocarpine or carbachol, changing the miotic therapy to echotiophate iodide improved pressure in $60 \%$ of the eyes ${ }^{43}$. Unfortunately, the drug cannot be used in younger patients, because of the degree of miosis and accommodative spasm. 


\section{Beta agonists and ciliary muscle tone}

$\beta$-adrenergic agonists are considered to increase the outflow facility via activation of the $\beta$-receptors. To our best knowledge, only one study that used organ culture eyes ${ }^{22)}$, showed increased outflow facility during the perfusion of epinephrine. However, there is no report in the literature that $\beta$-agonists increase the outflow facility in enucleated animal eyes ${ }^{66)}$. More interestingly, the outflow facility rather decreased by increasing the concentration up to $10^{-3} \mathrm{M}$. No report has shown that the trabecular meshwork is innervated, although slight staining of peptides and purines ${ }^{56,71)}$ is evident.

Adrenergic nerve stimulation decreases the outflow facility in monkeys but has no effect on uveoscleral outflow. Interestingly, adrenergic agonists do not mimic the effects of adrenergic nerve stimulation. Adrenergic drugs ${ }^{42,49)}$ may directly affect the trabecular meshwork and the uveoscleral outflow, perhaps via release of prostaglandings ${ }^{9,61)}$.

\section{Phosphodiesterase (PDE) inhibitors, ciliary muscle, and outflow channels}

Regarding adrenergic effects, many other inconsistencies exist in the field of IOP regulation and related intraocular muscle study. How do adrenergic agonists and antagonists lower IOP ? To our knowledge, few experiments using enucleated animal eyes have been carried out and the mechanism of IOP reduction is open to question despite many experiments using living animals. Why is the adrenergic nerve supply scarce in the human trabecular meshwork, although topical epinephrine has long been used clinically? Does this mean only that the trabecular meshwork has $\beta$ receptors that are not related to adrenergic innervation? If adrenergic effects occur via release of PGs, thereby decreasing IOP, then does adrenergic influence on IOP reduction occur via uveoscleral route?

Furthermore, why is adrenergic relaxation of the ciliary muscle small or even nil ${ }^{59)}$ (Fig. 8),

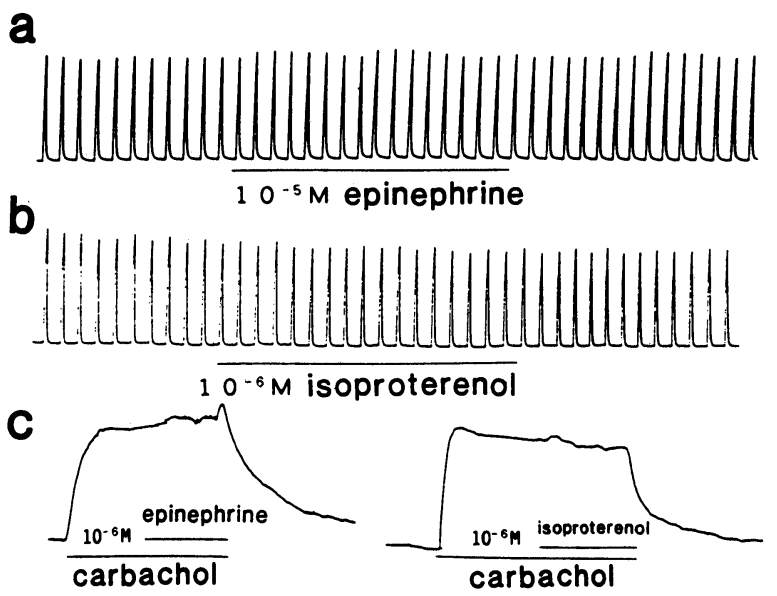

Fig. 8. Effects of epinephrine and isoproterenol on nerve-mediated contractions $(a, b)$ and carbachol-induced precontraction (c) of the bovine ciliary muscle. 
Table 3. Effects of $\beta$ agonists and PDE inhibitors on Ciliary Muscle, Outflow Facility and Cell Shape Change ofTrabecular Meshwork

\begin{tabular}{|c|c|c|c|c|}
\hline & $\beta_{1}$ agonists & $\beta_{2}$ agonists & $\beta$ agonists & PDE inhibitors \\
\hline & dobutamine & salbutamol & $\begin{array}{l}\text { epinephrine } \\
\text { isoproterenol }\end{array}$ & $\begin{array}{c}\text { theophylline } \\
\text { IBMX, caffeine } \\
\text { zaprinast }\end{array}$ \\
\hline ciliary muscle: tone & $\rightarrow \quad$ & $\rightarrow$ & $\rightarrow \quad \searrow$ & $\downarrow$ \\
\hline $\begin{array}{l}\text { ciliary muscle: } \\
\text { nerve-mediated } \\
\text { contraction }\end{array}$ & $\rightarrow \quad \searrow$ & $\rightarrow$ & $\rightarrow$ & $\downarrow$ \\
\hline cell shape change & ++ & - & + & $++t$ \\
\hline outflow facility & $\rightarrow \searrow \pi$ & $\rightarrow$ & $\rightarrow \searrow \begin{array}{l}* \\
\eta\end{array}$ & $\uparrow \uparrow$ \\
\hline
\end{tabular}

PDE: phosphodiesterase

although most smooth muscles are reciprocally innervated and the ciliary muscle greatly relaxes with PDE inhibitors. Theopylline inhibited the nerve-mediated contraction of the ciliary muscle, and also reduced the tension of the pre-contracted bovine ciliary muscle by carbachol $^{35)}$. In contrast, adrenergic drugs (epinephrine, isoproterenol, dobutamine, and salbutamol) had only a small effect on the ciliary muscle and the outflow facility of the eye ${ }^{66)}$.

It is beyond the scope of this brief review to describe the effects of drugs on the intraocular smooth muscle tone, nerve-mediated contractions, and cell shape changes of the smooth muscle, or the trabecular meshwork and to search for the physiologic and clinical meanings. Only an example is provided in Table 3. Why do PDE inhibitors play a much greater role than adrenergic agonists ${ }^{35,66,74,75)}$ ? Does this mean that an intracellular increase of cGMP occurs as a result of the application of PDE inhibitors, including zaprinast, in addition to the increased cAMP concentration? Species differences make these problems extremely difficult to solve, but they should be addressed in the future.

In considering the effects on IOP, each of these transmitters or modulators may have ocular sites of action and may induce significant net changes in IOP that do not necessarily reflect their potential effects on individual intraocular muscles.

Multiple factors should influence aqueous humor outflow, IOP, and intraocular muscle function. The narrow range and stability of normal IOP suggest that this system somehow is regulated $^{58)}$, although few data are available on the metabolic control of outflow facility ${ }^{65)}$ A possible regulatory system probably incorporates a feedback loop consisting of a sensory or afferent pathway and an efferent pathway through the autonomic nervous system. It should be clarified how the IOP, aqueous outflow rate, and intraocular muscles are moderated. The discoveries of neuropeptides and purines, the effects on outflow facility and intraocular muscles, and the association of cell shape change, intraocular muscle contraction with outflow facility, and especially animal species differences, all indicate a previously unappreciated heterogeneity and complexity of the ocular innervation and the mechanisms governing IOP and intraocular muscle physiology ${ }^{53,59,68)}$. 


\section{Acknowledgements}

We thank L. Charters, of Medical International for editing this manuscript.

\section{References}

1) Acott, T.S., Kingsley, P.D., Samples, J.R. and van Buskirk, E.M. (1988). Human trabecular meshwork organ culture: morphology and glycosaminoglycan synthesis. Invest. Ophthalmol. Vis. Sci. 29: 90-100.

2) Acott, T.S. (1994). Biochemistry of aqueous humor outflow. Section 4. In: Glaucoma, ed. by P.L. Kaufman and T.W. Mittag, Mosby, London, St. Louis, pp. 1/47-1/78.

3) Alm, A. and Villumsen, J. (1991). PhXA34, a new potent ocular hypotensive drug: A study on dose-response relationship and on aqueous humor dynamics in healthy volunteers. Arch. Ophthalmol, 109 : 1564-1568.

4) Barany, E.H. (1953). In vitro studies of the resistance to flow through the angle of the anterior chamber. Acta. Soc. Med. Upsal. 59: 260-276.

5) Bill, A. (1970). Effects of norepinephrine, isoproterenol, and sympathetic stimulation on aqueous humor dynamics on vervet monkeys. Exp. Eye Res. 10: 31-46.

6) Bill, A. (1984). Physiology of the outflow mechanism. In: Applied pharmacology in the medical treatment of glaucomas, ed. by S.M. Drance, Grune \& Stratton, Orlando, pp. 111-143.

7) Brubaker, R.F. (1975). The effect of intraocular pressure on conventional outflow resistance in the enucleated human eye. Invest. Ophthalmol. 14: 286-292.

8) Camras, C.B., Bito, L.Z. and Eakins, K.E. (1977). Reduction of intraocular pressure by prostaglandins applied topically to the eyes of conscious rabbits. Invest. Ophthalmol. Vis. Sci. $16: 1125-1134$.

9) Camras, C.B., Siebold, E.C. and Lustgarten, J.S. (1989). Maintained reduction of intraocular pressure by prostaglandin F $2 \alpha$-1-isopropylester applied in multiple doses in ocular hypertensive and glaucoma patients. Ophthalmology 96 : 1329-1337.

10) Chen, J. and Woodward, D.F. (1992). Prostanoid-induced relaxation of precontracted cat ciliary muscle is mediated by EP2 and DP receptors. Invest. Ophthalmol. Vis. Sci. 33 : 31953201.

11) Coroneo, M.T., Korbmacher, C. and Flugel, C. (1991). Electrical and morphological evidence for heterogeneous populations of cultured bovine trabecular meshwork cells. Exp. Eye Res. 52: $375-388$.

12) Crawford, K.S. and Kaufman, P.L. (1991). Dose-related effects of prostaglandin F2 $\alpha$ isopropylester on intraocular pressure, refraction and pupil diameter in monkeys. Invest. Ophthalmol. Vis. Sci. 32: 510-519.

13) Crean, E., Sherwood, M. and Casey, R. (1986). Establishment of calf trabecular meshwork cell cultures. Exp. Eye Res. 45 : 503-512.

14) Denis, P., Dussaillant, M., Nordmann, J.P., Elena, P.P. and Saraux, H. (1991). Autoradiographic characterization and localization of vasoactive intestinal peptide binding sites in albino rat and rabbit eyes. Exp. Eye Res. 52: 357-366.

15) Drago, F. (1985). Effects of opiates on intraocular pressure of rabbits and humans. Clin. Exp. Pharmacol. Physiol. 12 : 107-113.

16) Emi, K., Pederson, J.E. and Toris, C.B. (1989). Hydrostatic pressure of the suprachoroidal space. Invest. Ophthalmol. Vis. Sci. $30: 233-238$.

17) Epstein, D.L., Hashimoto, J.M. and Anderson, P.J. (1981). Effect of iodoacetamide perfusion on the outflow facility of the eye. Invest. Ophthalmol. Vis. Sci. 20: 625-631. 
18) Epstein, D.L. (1994). Examination of the eye in glaucoma. In: Chandler and Grant's Glaucoma, ed. by D.L. Epstein, Lea \& Febiger, Philadelphia, pp. 14-101.

19) Erickson-Lamy, K.A. and Schroeder, A. (1990). Dissociation between the effect of aceclidine on outflow facility and accommodation. Exp. Eye Res. 50: 143.

20) Erickson-Lamy, K., Korbmacher, C., Schuman, J. and Nathanson, J. (1991). Effect of endothelin on outflow facility and accommodation in the monkey eye in vivo. Invest. Ophthalmol. Vis. Sci. 32 : 492-495.

21) Erickson-Lamy, K.A. (1994). Basic aspects of parasympathetic pharmacology. chapter 65. In : The glaucomas, ed. by R. Ritch, M.B. Schields and T. Krupin, Mosby, St' Louis, pp. 13851407.

22) Erickson-Lamy, K.A. and Nathanson, J.A. (1996). Epinephrine increases facility of outflow and trabecular meshwork cAMP content in the human eye in vitro. Invest. Ophthalmol. Vis. Sci., In press.

23) Ethier, C.R., Coloma, F.M., de Kater, A.W. and Allingham, R.R. (1992). Retroperfusion studies of the aqueous outflow system. Part 1: Evaluation of technique using N-ethyl maleimide. Invest. Ophthalmol. Vis. Sci. 34: 385-394.

24) Gabelt, B.T. and Kaufman, P.L. (1990). The effect of prostaglandin F2 $\alpha$ on trabecular outflow facility in cynomolgus monkeys. Exp. Eye Res. 51: 87-91.

25) Grant, W.M. (1951). Clinical measurements of aqueous outflow. Arch. Ophthalmol. 46: 113131.

26) Grant, W.M. (1955). Facility of flow through the trabecular meshwork. Arch. Ophthalmol. 54: $245-248$.

27) Grierson, I., Robins, E. and Howes, R.C. (1980) Preliminary observations on human trabecular meshwork cells in vitro. Alb von Graefes. Arch. Klin. Exp. Ophthalmol. 212, 173186.

28) Hirai, R., Tamamaki, N., Hukami, K. and Nojyo, Y. (1994). Ultrastructural analysis of tyrosine hydroxylase, substauce $\mathrm{P}$, and calcitonin gene-related peptide immunoreactive nerve fibers in the rat iris. Ophthalmic. Res. 26: 169-180.

29) Honkanen, R.R., Howard, E.F. and Abdel-Latif, A.A. (1989) Characterization of muscarinic receptors in the bovine iris sphincter using oligonucleotides specific for the M1-M2 subtypes. Invest. Ophthalmol. Vis. Sci. 30 (Suppl) : 268.

30) Hosoki, R., Hisayama, T. and Takayanagi, I. (1987). Pharmacological evidence for the possible coexistence of multiple receptor sites for mammalian tachykinins in rabbit iris sphincter smooth muscle. Naunyn-Schmiedeberg Arch. Pharmacol. 335 : 290-295.

31) Kaufman, P.L. and Barany, E.H. (1976) Loss of acute pilocarpine effect on outflow facility following surgical disinsertion and retrodisplacement of the ciliary muscle from the scleral spur in the cynomolgus monkey. Invest. Ophthalmol. Vis. Sci. 15: 793.

32) Kaufman, P.L. and Mittag, T.W. (1996). Medical therapy of glaucoma. section 2. In : Glaucoma, ed. by P.L. Kaufman and T.W. Mittag, London, St. Louis, pp. 9/7-9/30.

33) Kawa, J.E., Higginbotham, E.J., Chang, I.L. and Yue, B.Y. (1993) Effects of antiglaucoma medications on bovine trabecular meshwork cells in vitro. Exp. Eye Res. 57 : 557-565.

34) Konno, F. and Takayanagi, I. (1986). Comparison of the muscarinic cholinoceptors in the rabbit ciliary body and the guinea-pig ileum. Eur. J. Pharmacol. 132 : 171-178.

35) Kubo, C., Suzuki, R., Yoshino, H. and Kurimoto, S. (1994). Theophylline and caffeine influence the ciliary muscle and the outflow facility of the eye. Excepta Medica. In : Current Aspects in Ophthalmology, vol 2, ed. by K. Shimizu, Elsevier Science Publishers BV, Amsterdam, pp. 1355-1360.

36) Lepplewienhues, A., Stakl, F. and Wiederholt, M. (1991) Differential smooth muscle-like contractile properties of trabecular meshwork and ciliary muscle. Exp. Eye Res. 53: 33-38. 
37) Lograno, M.D. and Reibaldi, A. (1986) Receptor responses in fresh human ciliary muscle. Br. J. Pharmacol. $87: 2$.

38) Lograno, M.D., Giovanazzi, D.S., Guarrera, A. and Nicosia, S. (1992). Effects of prostaglandins and PAF on the contractility of the bovine ciliary muscle. Pharmacol. Res. 25 : 195-202.

39) Lutjen-Drecoll, E. and Tamm, E. (1988). Morphological study of the anterior segment of cynomolgus monkey eyes following treatment with prostaglandin F2 $\alpha$. Exp. Eye Res. 47 : 761-769.

40) MacCumber, M.W., Jampel, H.D. and Snyder, S.H. (1991). Ocular effects of the endothelines : Abundant peptides in the eye. Arch. Ophthalmol. 109: 705-709.

41) Masuda, Y., Yamahara, N.S., Tanaka, M., Ryang, S. and Watanabe M. (1995). Characterization of muscarinic receptors mediating relaxation and contraction in the rat dilaor muscle. Br. J. Pharmacol. 114 : 769-776.

42) Mittag, T.W. (1996). Adrenergic and dopaminergic drugs in glaucoma. In: The glaucomas, ed. by R. Ritch, M. Shields and T. Krupin, CV Mosby Co, St Louis, pp. 523-537.

43) Nardin, G.F. and Zimmerman, T.J. (1996). Ocular cholinergic agents. In: The Glaucomas, ed. by R. Ritch, M. Shields and T. Krupin, CV Mosby Co, St. Louis, pp. 1399-1407.

44) Narita, S. and Watanabe, M. (1982). Response of isolated rat iris dilator to adrenergic and cholinergic agents and electrical stimulation. Life Sci. 30 : 1211-1216.

45) Nilsson, S.F.E., Sperber, G.O. and Bill, A. (1986). Effects of vasoactuie intestinal polypeptide (VIP) on intraocular pressure, facility of outflow and formation of aqueous humor in the monkey. Exp. Eye Res. $43: 5$.

46) Nilsson, S.F.E., Samuelsson, M., Bill, A. and Stjernschantz, J. (1989). Increased uveoscleral outflow as a possible mechanism of ocular hypotension caused by prostaglandin F $2 \alpha-1$ isopropyl ester in the cynomolgus monkey. Exp. Eye Res. 48: 707-715.

47) Nilsson, S.F.E. and Bill, A. (1994). Physiology and neurophysiology of aqueous humor inflow and outflow. In: Glaucoma, ed. by P.L. Kaufman and T.W. Mittag, Mosby, London, St. Louis, pp. 17-34.

48) Polansky, J.A., Wood, I.S., Maglio, M.T. and Alvarado, J.A. (1984). Trabecular meshwork cell culture in glaucoma research : evaluation of biological activity and structural properties of human trabecular cells in vitro. Ophthalmology 91: 580.

49) Potter, D.E. and Rowland, J.M. (1978). Adrenergic drugs and intraocular pressure : Effects of selective $\beta$-adrenergic agonists. Exp. Eye Res. 27 : 615-625.

50) Poyer, J.F., Millar, C. and Kaufman, P.L. (1995). Prostaglandin F2 $\alpha$ effects on isolated rhesus-monkey ciliary muscle. Invest. Ophthalmol. Vis. Sci. 36: 2461-2465.

51) Reichert, R.W. and Shields, M.B. (1991) Intraocular pressure response to the replacement of pilocarpine or carbachol with echothiophate. Graefes. Arch. Clin. Exp. Ophthalmol. 229 : 252.

52) Rosenberg, P., Higman, H. and Nachmansohn, D. (1960). An improved isolated single electroplax preparation. 1. Effect of compounds acting primarily at the synapses. Biochim. Biophys. Acta 44 : 151-160.

53) Ryang, S., Takei, S., Kawai, T., Imaizumi, Y. and Watanabe, M. (1990). Atropine-resistant relaxation induced by high $\mathrm{K}+$ in iris dilator of the rat and pig. Br. J. Pharmacol. 100 : 401406.

54) Schuman, J., Erickson Lamy, K. and Nathanson, J.A. (1994). Nitrovasodilator effects on intraocular pressure and outflow facility in monkeys. Exp. Eye Res. 58: 99-105.

55) Shiraishi, K. and Takayanagi, I. (1993) Subtype of muscarinic receptors mediating relaxation and contraction in the rat iris dilator smooth muscle. Gen. Pharmacol. 24 : 139-142.

56) Stone, R.A., Kuwayama, Y. and Laties, A.M. (1987). Regulatory peptides in the eye. Experientia 43 : 791-800.

57) Stone, R.A., Laties, A.M., Raviola, E. and Wiesel, T.N. (1988) Increase in retinal vasoactive 
intestinal polypeptide after eyelid fusion in primates. Proc. Natl. Am. S. US. 85: 257-260.

58) Stone, R.A. (1994). Nervous system and intraocular pressure. In: The Glaucomas, ed. by R. Ritch, M.B. Schields and T. Krupin, Mosby, St. Louis, Baltimore, chapter 17, pp. 357-383.

59) Suzuki, R. (1983). Neuronal influence on the mechanical activity of the ciliary muscle. $B r$. J. Pharmacol. 78 : 591-597.

60) Suzuki, R. and Kobayashi, S. (1983). Cholinergic inhibitory response in the iris dilator muscle. Invest. Ophthalmol. Vis. Sci. 24: 760-765.

61) Suzuki, R. and Kobayashi, S. (1983). Response of bovine intraocular muscles to transmural stimulation in the presence of various prostaglandins. Exp. Eye Res. 36: 789-798.

62) Suzuki, R. and Kobayashi, S. (1984). Different effects of substance P and vasoactive intestinal peptide on the motor function of bovine intraocular muscles. Invest. Ophthalmol. Vis. Sci. 24 : 1566-1572.

63) Suzuki, R., Yoshino, H. and Kobayashi, S. (1987). Different time courses of bovine iris sphincter and dilator muscles after stimulation. Ophthalm. Res. 19 : 344-350.

64) Suzuki, R. and Kobayashi, S. (1989). Possible mechanisms related to contraction of the bovine iris sphincter in the presence of acetylcholine and carbachol. Doc. Ophthalmol. 70 : 293-300.

65) Suzuki, R. and Anderson, P.J. (1994). A temperature dependent action of fluoride on aqueous outflow facility of the calf eye. Curr. Eye Res. 12: 1-7.

66) Suzuki, R., Karageuzian, T., Crean, E. and Anderson, P.J. (1996). Adrenergic influence on outflow facility and shape of cells of bovine trabecular meshwork tissue. Ophthalmology 40 : 4.

67) Takayanagi, I., Saitoh, K., Koike, K. and Satoh, M. (1991). Characterization of muscarinic receptors in rabbit ciliary body smooth muscle using propylbenzilylcholine mustard. Gen. Pharmacol. 22: 851-853.

68) Takayanagi, I., Shiraishi, K. and Satoh, M. (1992). Effects of ageing on responses of rabbit iris smooth muscles to agonists and field stimulation. Gen. Pharmacol. 23 : 463-469.

69) Tamm, E.R., Fliigel, C., Stefani, F.H. and Liitjen-Drecoll, E. (1994). Nerve endings with structural characteristics of mechanoreceptors in the human scleral spur. Invest. Ophthalmol. Vis. Sci. 35 : 1157-1166.

70) Tripathi, B.J. and Tripathi, R.L. (1984). Effect of epinephrise in vitro on the morphology, phagocytosis and miotic activity of human trabecular endothelium. Exp. Eye Res. 33: 731744.

71) Uusitalo, H., Lehtosalo, J.I. and Palkama, A. (1985). Vosoactive intestinal polypeptide (VIP)-immunoreactive nerve fibers in the anterior uvea of the guinea-pig. Ophthalmic. Res. $\mathbf{1 7}: 4$.

72) van Alphen, G.W.H.M., Wilhelm, P.B. and Elsenfeld, P.W. (1977). The effect of prostaglandins on the isolated internal muscles of the mammalian eye, including man. Doc. Ophthalmol. 42 : $397-415$.

73) Villumsen, J., Alm, A. and Soderstrom, M. (1989). Prostaglandin F2 $\alpha$-isopropylester eye drops: Effect on intraocular pressure in open-angle glaucoma. Br. J. Ophthalmol. 73: 975979.

74) Wax, M.B., Molinoff, P.B. and Alvarado, J. (1989) Characterization of $\beta$-adrenergic receptors in culture human trabecular cells and in human trabecular meshwork. Invest. Ophthalmol. Vis. Sci. $30: 51-57$.

75) Weinreb, R.N. and Ryder, M.I. (1990). In situ localization of cytoskeletal elements in the human trabecular meshwork and cornea. Invest. Ophthalmol. Vis. Sci. 31: 1839-1847.

76) Williamson, T.H. and Harris, A. (1994). Ocular blood-flow measurement. Br. J. Ophthalmol. 78 : 939-945. 
77) Yoshitomi, T., Ito, Y. and Inomata, H. (1985). Adrenergic excitatory and cholinergic inhibitory innervations in the human iris dilator. Exp. Eye Res. $40: 3$.

78) Yoshitomi, T. and Ito, Y. (1986) Presynaptic actions of noradrenaline on the dog ciliary muscle tissue. Exp. Eye Res. $43: 1$.

79) Yoshitomi, T. and Ito, Y. (1988). Effects of indomethacin and prostaglandins on the dog iris sphincter and dilator muscles. Invest. Ophthalmol. Vis. Sci. 29: 127-132.

80) Yoshitomi, T., Ishikawa, H., Haruno, I. and Ishikawa, S. (1995). Effect of histamin and 21) Erickson-Lamy K.A. (1996). Basic aspects of parasympathetic pharmacology. chapter 65. In: The glaucomas, ed. by R. Ritch, M.B. Schields and T. Krupin, Mosby, St' Louis, pp. 13851407.

81) Yousufzai, S.Y.K., Zheng, P. and Abdel-Latif, A.A. (1994). Muscarinic stimulation of arachidonic acid release and prostaglandin synthesis in bovine ciliary muscle: prostaglandins induce cyclic AMP formation and muscle relaxation. Exp. Eye Res. 58: 513-522.

82) Zhang, X. (1995). Expression of muscarinic receptor subtype mRNA in the human ciliary muscle. Invest. Ophthalmol. Vis. Sci. $36: 1645$. 